ORIGINAL ARTICLE

\title{
Primary osteoarthritis and occupations: a national cross sectional survey of 10412 symptomatic patients
}

\author{
M Rossignol, A Leclerc, P Hilliquin, F A Allaert, S Rozenberg, J-P Valat, B Avouac, P Coste, \\ B Savarieau, B Fautrel
}

Occup Environ Med 2003;60:882-886

See end of article for authors' affiliations

Correspondence to:

Dr M Rossignol, Montreal

Department of Public

Health, 1301 Sherbrooke

Street East, Montreal,

Quebec, Canada H2L

1M3; mrossign@

santepub-mil.qc.ca

Accepted

12 November 2002

\begin{abstract}
Aims: To describe the age standardised prevalence of symptomatic osteoarthritis (OA) in a nationwide cross sectional survey of 10412 patients in France, and their functional and work limitations.

Methods: Cases in the survey were compared with their expected counterpart by age, gender, and occupational groupings using data from the 1998 French National Survey on Health Impairment and Disability.

Results: Women represented $66.2 \%$ of the sample; mean age was 66.2 years. One third of patients had OA of the knee, $16 \%$ of the hip, and $12 \%$ of the hand; a third had multiple joint OA. Peak prevalence of symptomatic OA was in the 60-69 year category in women and in the 70-79 year category in men. Agricultural workers showed a significant excess prevalence of $O A$, with an observed to expected (O/E) ratio of 1.7 in women and 2.3 in men. Linear trends in prevalences between white collar, "mixed" collar, and blue collar workers were also significant, with odds ratios respectively of 1.0, 2.9, and 2.6 in women and 1.0, 1.2, and 1.7 in men. Specific excess prevalence was found in women among housekeepers $(\mathrm{O} / \mathrm{E}$ 4.4), and in men among unskilled labour workers (O/E 10.3) and truck drivers (O/E 6.7). Total work disability was highest among blue collar workers and partial disability among agricultural workers. Conclusion: Results contribute to the mounting evidence that $O A$ is potentially aetiologically linked to occupation in a sizeable segment of the population and that $\mathrm{OA}$ can no longer be considered an inevitable disease of ageing.
\end{abstract}

$\mathrm{T}$ he relation between osteoarthritis (OA) and occupation is made difficult by a long latency before the pathological process brings individuals to medical consultation and to functional and work incapacity, and by ill defined occupational exposures. This can explain in part the discrepancies in results of early with more recent epidemiological studies on the subject. ${ }^{1}$ Better definition of osteoarthritis and better selection of subjects and controls have made it possible to describe specific ergonomic factors associated with the development of OA. ${ }^{2-4}$

Data from large national cross sectional surveys have been used to document the nature of occupational risks of OA and helped describe the age pattern underlying the association..$^{5-8}$ We had the opportunity to use data from a national cross sectional pharmacoepidemiological survey of over $10000 \mathrm{OA}$ patients which combined information on occupation and functional and work disability. The large size of this survey and its national representativity permitted determination of age specific patterns in different occupational groups.

The objectives of this study were: (1) to describe the age distribution of symptomatic OA in men and women; (2) to describe the prevalence of OA in occupations by comparing the number of cases observed with that expected from the population distribution; and (3) to describe the functional and work limitations of patients with OA.

\section{METHODS}

This study used data from a nationwide survey of 5254 physicians who treat OA patients. ${ }^{9}$ The goal of the main study was to describe the pharmacoepidemiology of OA treatment in France. The socioprofessional characteristics of these physicians were similar to that of all physicians in the country for age and type of practice, but males were slightly over-represented and physicians practising in urban environ- ments under-represented (table 1). Each of the physicians participating were asked to include their first two patients within 10 days of the onset of the study, who consulted for $\mathrm{OA}$ in at least one of the hip, knee, or hand joints, regardless of the current or past diagnostic method used on that patient. Recruitment of patients was completed in the months of October and November 2000. The survey was cross sectional in nature and $88.3 \%$ of the patients included were seen for a follow up medical visit at time of inclusion. Physicians filled out a questionnaire containing information on the medical history, clinical management including pharmacological and non-pharmacological treatments, functional status, and occupation of their two patients. Patients were asked to report the occupation they held the longest during their lifetime, whether or not they were occupationally active at the time of the survey.

The occupation of the patients were coded to correspond to the categories used in France. ${ }^{10}$ Codes were grouped into five categories: agriculture, white collar workers, blue collar workers, "mixed" collar workers, and workers in commercial services. The white, blue, and mixed categories were based on previous work that attempted to put together occupations with comparable levels of physical work. ${ }^{11}$ Briefly, the white collar worker category included liberal professions, managers, and administrators, the blue collar worker category included skilled and unskilled manual occupations, and the "mixed" category included workers who perform physical work outside industrial environments such as health, education, and secretarial (traditionally grouped under white collar workers). Commercial services included occupations related to direct commercial and other services, and agriculture grouped farm and horticultural workers.

The age (four categories), gender, and occupational (five categories) distribution of the patients (observed cases) was 
Main messages

- Primary osteoarthritis is related to occupations. Even though the aetiological link remains unclear, occupational risks during active life may be involved in a large number of patients after the age of retirement.

compared to that obtained from the National Survey on Health Impairment and Disability of 1998 in France. ${ }^{12}$ In this survey occupation was the current occupation for those employed, and the most significant occupation in the lifetime for those who were no longer employed. In each stratum, an expected number of patients was calculated by multiplying the national proportion of the adult population (over 18 years of age) in that cell by the total number of observed cases. The ratios of observed to expected number of cases were obtained for each age, gender, and occupational category. All analyses were performed separately for men and women. The reference ratio (1.0) represented the average distribution for the whole observed population. A ratio above one meant an excess in OA prevalence (relative prevalence) over what would be expected if the distribution of OA patients was similar to that of the general population for age, gender, and occupation (the null hypothesis). Confidence intervals (95\%) were obtained by using the square root approximation. ${ }^{13}$ Age standardised distribution of patients were then plotted separately for men and women contrasting the five occupational groups. A $\chi^{2}$ test for linear trend was used to contrast the relative prevalence between the white, mixed, and blue collar worker categories with a hypothesis that increased physical work load is associated with greater OA prevalence.

\section{RESULTS}

Of the 10412 patients included in the study, two thirds were women $(66.2 \%)$ and the mean age was 66.2 years (SD 10.2) (table 2). OA was reported to begin on average at 57.0 years of age (SD 9.6) with no difference between men and women. Because the participating physicians enrolled their first two patients who would volunteer and did not keep an account of those who did not, we have no indication of the participation rate. The OA diagnosis was confirmed with at least a plain $x$ ray examination in $91.2 \%$ of the patients included; the other $8.8 \%$ had either had an $x$ ray examination done by another physician or were diagnosed clinically only. The average duration of OA was almost 10 years. The knee was the most affected joint; knee OA occurred in one third of patients who had a single OA complaint, which was twice as many as either the hip or the hand ( $15.7 \%$ and $11.6 \%$ respectively). The last third represented multiple joint involvement (37.1\%). Men had a frequency of hip involvement (19.6\%) almost twice that of women (11.4\%), and women had a higher proportion of hand OA (9.2\%) than men (3.9\%) (fig 1).

Information on the longest held occupation during the lifetime was unavailable for $38.1 \%$ of women and $9.6 \%$ of men. In women, $38 \%$ of the missing information was in the 70-79 age category. These survey participants were not excluded from the analyses and were categorised as "occupation missing" (not shown in the results). This category included homemakers, individuals who did not report holding a job for any significant length of time in their lifetime, and individuals whose physician did not ask or did not report the information.

The age and occupational distribution of OA patients is shown in table 3 for women and table 4 for men. Both showed very similar age distribution, with the largest observed/expected ratio between 70 and 79 years of age.
Policy implications

- Preventive measures need to be developed in the workplace in order to reduce the burden of osteoarthritis in populations.

Table 1 Socioprofessional characteristics of physicians participating in the survey $(n=5254)$

\begin{tabular}{lll}
\hline & $\begin{array}{l}\text { Physicians in } \\
\text { survey }\end{array}$ & $\begin{array}{l}\text { All physicians in } \\
\text { France }\end{array}$ \\
\hline Age (mean) & 46.4 & 46.7 \\
Gender (\% males) & 83.9 & 74.1 \\
Practice (\%) & 49.9 & 66.9 \\
$\quad$ Urban & 28.8 & 11.4 \\
Semi-urban & 21.3 & 21.7 \\
$\quad$ Rural & & \\
Specialty (\%) & 90.3 & 94.3 \\
$\quad$ General practice & 9.7 & 5.7 \\
$\quad$ Rheumatology & & \\
Type of consultation for & & - \\
patients included (\%) & 11.7 & - \\
$\quad$ Initial & 88.3 & \\
$\quad$ Follow up & & \\
\hline
\end{tabular}

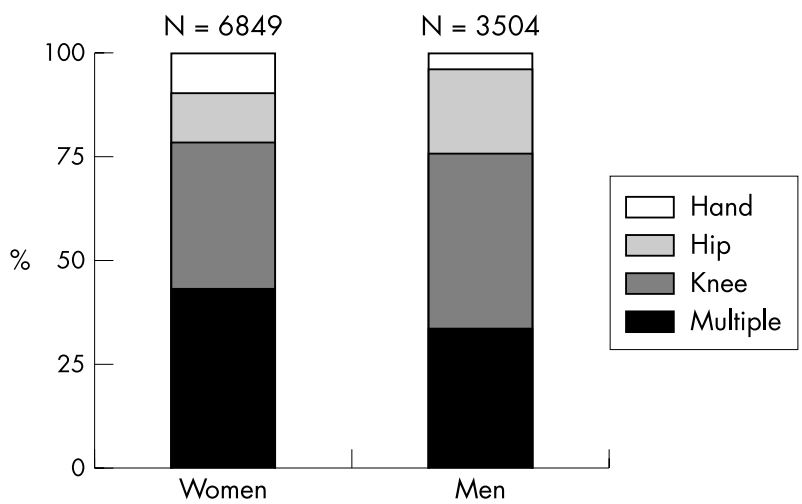

Figure 1 Site of osteoarthritis by gender.

Graphically, excess OA peaked in women between 60 and 69 in all occupations and seemed to remain relatively constant in the following age category with almost no excess after the age of 80 (fig 2). In men the same pattern was observed, except for agricultural workers and blue collar workers where the OA excess doubled up further in the 70-79 age category, with an excess remaining after the age of 80 (fig 3).

Table 2 Characteristics of OA patients participating in the survey $(n=10412)$

\begin{tabular}{ll}
\hline Age, y (SD) & $66.2(10.2)$ \\
Gender (\% males) & 33.8 \\
Diagnostic x ray (\%) & 91.2 \\
Mean duration of OA, y (SD) & $9.3(6.8)$ \\
Joint involved (\%) & \\
Hand & 11.6 \\
Hip & 15.7 \\
Knee & 35.6 \\
More than one & 37.1 \\
\hline
\end{tabular}


Table 3 Relative prevalence of OA by age and occupation among women

\begin{tabular}{|c|c|c|c|c|c|c|}
\hline & All occupations & White collar* & Agriculture* & Blue collar* & "Mixed" collar" & Commercial services* \\
\hline Age & $n=6811$ & $n=236$ & $n=513$ & $n=566$ & $n=1692$ & $n=1154$ \\
\hline $20-59$ & 0.3 (0.3 to 0.3$)$ & $0.1(0.07$ to 0.11$)$ & $1.0(0.07$ to 1.2$)$ & $0.2(0.2$ to 0.3$)$ & $0.3(0.2$ to 0.3$)$ & 0.2 (0.2 to 0.2$)$ \\
\hline $60-69$ & 2.6 (2.5 to 2.7 ) & $1.2(0.9$ to 1.5$)$ & 2.2 (1.9 to 2.5$)$ & $1.6(1.4$ to 1.8$)$ & 2.5 (2.3 to 2.7$)$ & 1.8 (1.6 to 2.0$)$ \\
\hline $70-79$ & 3.1 (2.9 to 3.2 ) & $1.0(0.8$ to 1.3$)$ & 2.2 (1.9 to 2.4$)$ & $1.2(1.1$ to 1.4$)$ & 2.3 (2.1 to 2.5 ) & 1.9 (1.7 to 2.2$)$ \\
\hline $80+$ & $1.7(1.5$ to 1.8$)$ & $0.6(0.4$ to 0.9$)$ & $0.8(0.6$ to 1.1$)$ & $0.7(0.5$ to 0.8$)$ & $1.1(0.9$ to 1.3$)$ & 0.8 (0.7 to 1.0$)$ \\
\hline Age standardised & 1.0 & $0.2(0.2$ to 0.3$)$ & $1.7(1.5$ to 1.8$)$ & $0.6(0.5$ to 0.6$)$ & $0.7(0.6$ to 0.7$)$ & $0.8(0.7$ to 0.8$)$ \\
\hline
\end{tabular}

Ratios observed/expected $(95 \% \mathrm{Cl}) ; \mathrm{n}=$ number observed. Expected numbers obtained using the age, gender, and occupational distribution from the 1998 French National Survey on Health Impairment and Disability.

*White collar worker category included liberal professions, managers, and administrators. Agriculture included grouped farm and horticulture workers. Blue collar worker category included skilled and unskilled manual occupations. "Mixed" category included workers who perform physical work outside industrial environments such as health, education, and secretarial. Commercial services grouped occupations related to direct commercial and other services.

The only occupational category that showed a prevalence of $\mathrm{OA}$ in excess of the average (all age categories combined) was agriculture with an observed/expected (O/E) ratio of 1.7 (95\% confidence interval (CI) 1.5 to 1.8 ) in women (table 3 ) and 2.3 in men (95\% CI 2.1 to 2.5 ) (table 4). Graphically however, differences between occupational groups interacted with age and revealed other particularities. In women (fig 2), all occupational groups had a higher $\mathrm{O} / \mathrm{E}$ ratio than the white collar workers category above 60 years of age. Women in agriculture started their OA at a young age with an O/E ratio three times higher than all occupations combined ( 1.0 versus 0.3 in table 3 ) in the 20-59 age category. Another observation in women was the excess OA in the "mixed" collar workers category after the age of 60 . This was essentially due to the housekeeping occupation, with a ratio O/E of 4.4 (95\% CI 2.7 to 6.5 ) in the 60-69 age category. It was also in that category that the highest proportion of hand OA was found (16.0\%). The test for linear trend between white, mixed, and blue collar worker categories was statistically significant $(p<0.001)$, with odds ratios of respectively 1.0, 2.9, and 2.6.

In men (fig 3), large differences between occupations were observed in the 70-79 age group where peak prevalence were found. In agricultural and blue collar workers, the excess OA in that age group was much higher in men than in women (4.1 versus 2.2 and 3.9 versus 1.2 respectively). In the blue collar workers category, two occupational groups stood out in finer analysis, industrial unskilled labour with a O/E ratio of 10.3 (95\% CI 8.7 to 12.1 ) in the 70-79 year old category, and motor vehicle drivers (mostly truck drivers, but also included bus and taxi drivers) with a ratio of 6.7 (95\% CI 4.6 to 9.1) in the same age category. Also noticeable on the graph was the excess OA observed in the white collar workers category between the age of 60 and 79, where the O/E ratio was much above 1.0 as opposed to what was seen for women. The test for linear trend between white, mixed, and blue collar worker categories was statistically significant $(\mathrm{p}<0.001)$ with odds ratios of, respectively, 1.0, 1.2, and 1.7.

\section{Functional and work limitation}

All aspects of functional limitation increased with age except for the leisure activities that were reported to be affected because of OA by over $75 \%$ of patients in all age groups (fig 4). The same observation on leisure activities was made when looking at the site of OA (fig 5). The impact of OA on personal care was also equally observed for all sites and rose very sharply with age.

Of the 10412 OA patients participating in the survey, 2116 were actively employed. Of those, $21.6 \%$ were on sick leave (total work disability) due to their OA and $44.2 \%$ reported some difficulty (partial work disability) performing their job. Figure 6 shows the distribution of total and partial disability by occupational group. Each group showed a different pattern. The least disabled from work were the white collar workers, with $62.6 \%$ without any work disability. On the other hand, the category with the lowest total disability from work was agricultural workers with $6.3 \%$. They also had the highest partial disability $(78.5 \%)$ along with the highest excess of $\mathrm{OA}$ of all occupational groups. The highest proportion of totally disabled workers due to OA was found in the blue collar worker category with $18.7 \%$, which was three times higher than agricultural workers. The "mixed" collar worker category showed a similarly high proportion of totally disabled workers among those who had a disability. Finally, commercial services workers had a disability pattern close to that of the blue collar worker category with somewhat less total disability and more partial disability.

\section{DISCUSSION}

The main finding of this study was that the excess prevalence of OA observed in occupational groups was not only associated with "exposure" to occupations, but was also the result of an evolution through time that included a latency between the pathological process and the time when OA patients reported their first symptoms and a natural history thereafter that was reported in this study to be on average 10

Table 4 Relative prevalence of OA by age and occupation among men

\begin{tabular}{|c|c|c|c|c|c|c|}
\hline \multirow[b]{2}{*}{ Age } & \multirow{2}{*}{$\begin{array}{l}\text { All occupations } \\
n=3480\end{array}$} & \multirow{2}{*}{$\begin{array}{l}\text { White collar* } \\
n=428\end{array}$} & \multirow{2}{*}{$\begin{array}{l}\text { Agriculture* }^{*} \\
\mathrm{n}=575\end{array}$} & \multirow{2}{*}{$\frac{\text { Blue collar* }}{n=1169}$} & \multirow{2}{*}{$\frac{\text { "Mixed" collar* }}{n=657}$} & \multirow{2}{*}{$\begin{array}{l}\text { Commercial services } \\
n=163\end{array}$} \\
\hline & & & & & & \\
\hline $20-59$ & $0.4(0.3$ to 0.4$)$ & $0.3(0.2$ to 0.3$)$ & $0.7(0.6$ to 0.9$)$ & $0.4(0.4$ to 0.4$)$ & $0.3(0.2$ to 0.3$)$ & 0.3 (0.2 to 0.3$)$ \\
\hline $60-69$ & 2.8 (2.6 to 2.9$)$ & 1.9 (1.6 to 2.2$)$ & 3.0 (2.6 to 3.4$)$ & 2.5 (2.2 to 2.7$)$ & $2.4(2.1$ to 2.8$)$ & 2.0 (1.5 to 2.6$)$ \\
\hline 70-79 & 3.6 (3.4 to 3.8$)$ & 2.2 (1.8 to 2.6$)$ & 4.1 (3.6 to 4.7$)$ & 3.9 (3.5 to 4.3$)$ & 2.6 (2.2 to 2.9 ) & 2.3 (1.7 to 3.0$)$ \\
\hline $80+$ & 2.1 (1.8 to 2.4$)$ & $1.1(0.7$ to 1.6$)$ & $2.4(1.7$ to 3.1$)$ & 2.2 (1.7 to 2.8$)$ & 1.7 (1.2 to 2.4$)$ & $1.1(0.5$ to 2.0$)$ \\
\hline Age standardised & 1.0 & $0.6(0.5$ to 0.7$)$ & 2.3 (2.1 to 2.5 ) & $1.0(0.9$ to 1.1$)$ & $0.7(0.7$ to 0.8$)$ & $0.6(0.5$ to 0.7$)$ \\
\hline
\end{tabular}

Ratios observed/expected $(95 \% \mathrm{Cl}) ; \mathrm{n}=$ number observed. Expected numbers obtained using the age, gender, and occupational distribution from the 1998 French National Survey on Health Impairment and Disability.

*White collar worker category included liberal professions, managers, and administrators. Agriculture included grouped farm and horticulture workers. Blue collar worker category included skilled and unskilled manual occupations. "Mixed" category included workers who perform physical work outside industrial environments such as health, education, and secretarial. Commercial services grouped occupations related to direct commercial and other services. 


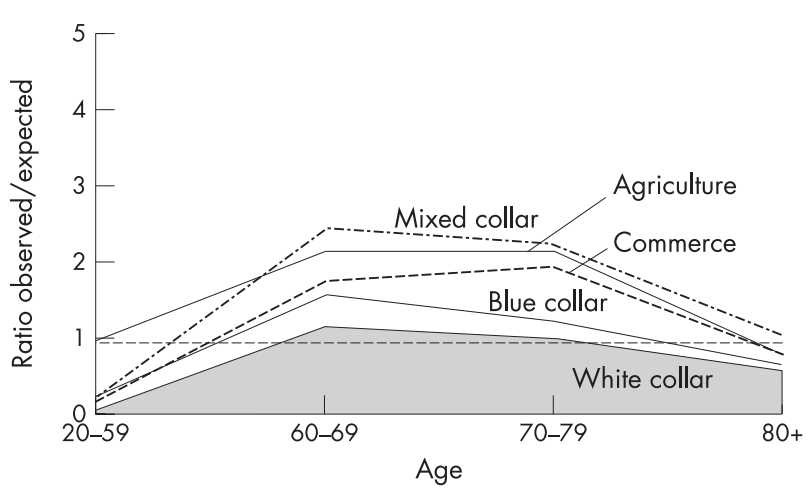

Figure 2 Osteoarthritis by age and profession; women.

years long. Over $80 \%$ of the population studied here became symptomatic from OA at or after the age of retirement, which would confer to the pathological process a latency in the range of 10-20 years. A particular case of this was seen among agricultural workers with a symptomatic stage that started before any other occupational groups and might be the result of a combination of exposure to particularly important stresses on the joints and of exposure at a young age. $^{14}$

Although cross sectional in nature, this study was, to our knowledge, the largest national survey of clinically symptomatic OA outpatients. It was made possible by a unique network of physicians for rheumatic diseases that has been in existence for many years in France. Participating physicians and their patients were representative of all regions and practices in the country. Because the primary goal of the study was not to look at occupations, we are confident that the distribution of occupations in OA patients was not biased compared to the general population. We did however have a large segment of our study population for which the occupation was unknown, especially among women in the 70-79 age category. Because of our confidentiality protocol, we were not able to describe their geographical distribution. Their inclusion as a separate category avoided removing them from the denominator in our calculations, which in turn

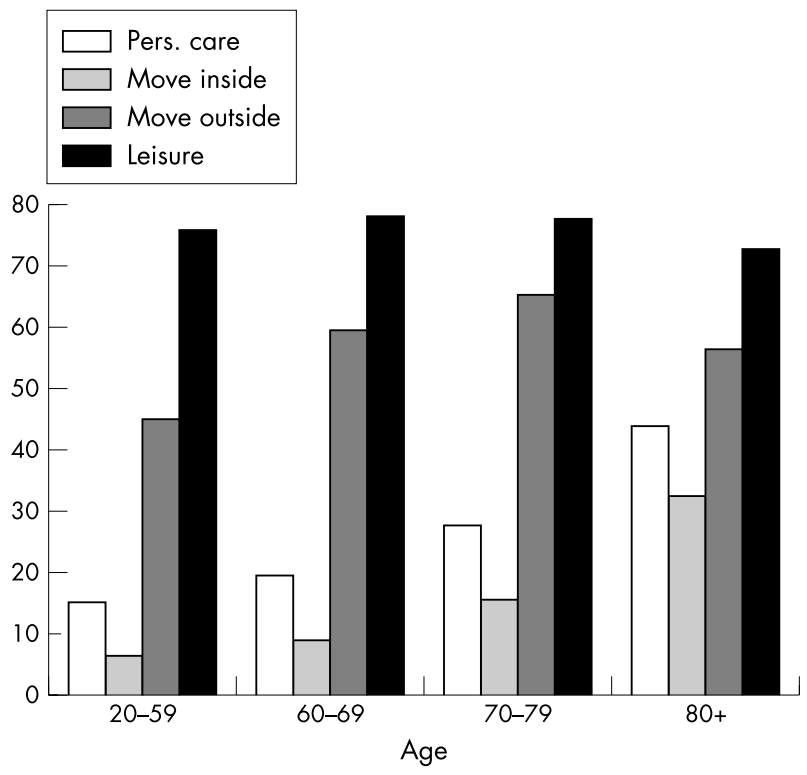

Figure 4 Limitations due to osteoarthritis by age.

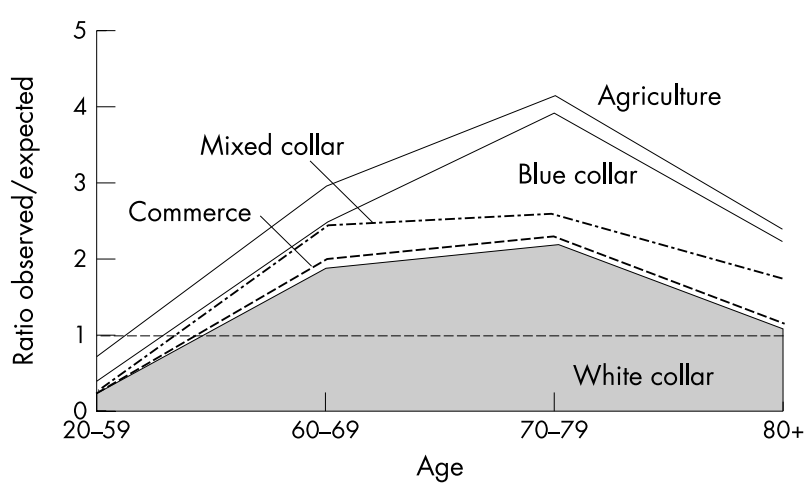

Figure 3 Osteoarthritis by age and profession; men.

underestimated the number of "observed" cases and the O/E ratios in the remaining occupational categories. The fact that there were four times more missing occupations among women than among men might explain in part the flattened aspect of the age distributions in women (fig 2) compared to men (fig 3).

Inclusion in this study was related to a consultation for symptomatic OA and was therefore dependent not only on the prevalence of $\mathrm{OA}$ in the population, but also on the consultation patterns which can be different between women and men and between younger and older patients. It is also possible that clinicians did not include their older patients because their OA complaint was one among many others and because they did not want to prolong a lengthy consultation. This might explain in part the apparent fall in the prevalence of symptomatic OA after 80 years of age.

This general survey did not provide information on specific occupational risk factors in the development of OA, but reinforced previous findings on agricultural workers, ${ }^{14}{ }^{15}$ housekeepers (cleaners), ${ }^{8}$ and general occupational categories with high physical demands. ${ }^{76}$ It also pointed at truck drivers as a new occupational group that had not been previously described as being at risk, except in one recent study where the general category of transportation showed some excess risk of knee arthroplasty. ${ }^{17}$ These findings are consistent with the hypothesis that specific ergonomic stresses such as knee bending, kneeling, and squatting may constitute long term stresses leading to OA. ${ }^{45}$ In our study,

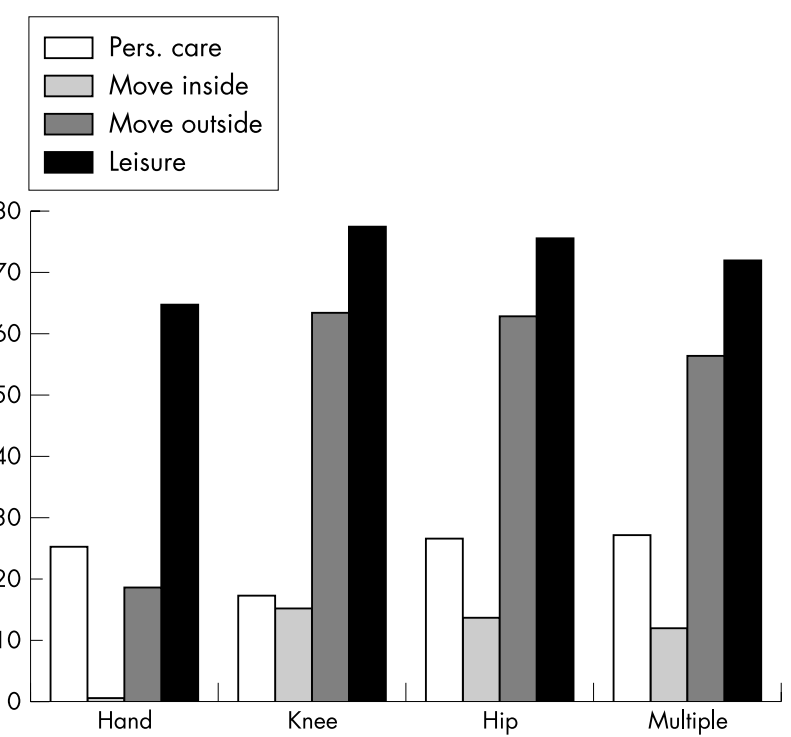

Figure 5 Limitations due to osteoarthritis by site. 


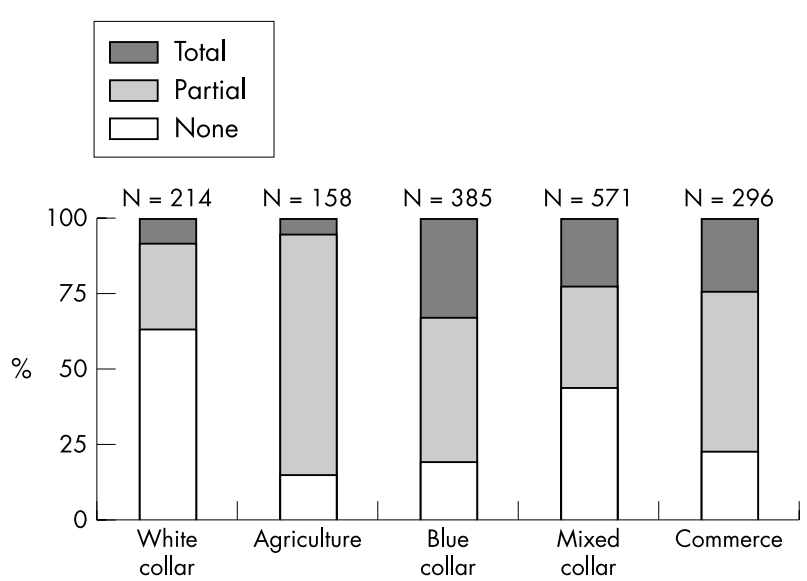

Figure 6 Work limitations due to osteoarthritis by profession (active population: $n=2116$ ).

we did not find specific distributions of OA by anatomical sites, in part because of the lack of precision in the occupational classification of our study subjects.

Occupational disability patterns found in the different categories were very interesting. They can be explained by the severity of the disease and also by economic and socioprofessional characteristics. It was found, for instance, that workers in the agricultural sector were very much affected in their work but were less likely than other occupational groups to use sick leave as an option. This area deserves more attention in future studies to determine the impact of disability alternatives on the progression of OA.

Finally, the results from this study were controlled for age and gender but not for other confounders such as body mass index, previous injury, co-morbidity, oestrogen use in women, and ergonomic risks outside work. ${ }^{18-20}$ However, with such a large sample size we feel confident that the hypotheses generated here are reasonable and deserve specific attention in future studies.

In summary, the descriptive analysis of this large data set provided arguments in favour of the following hypotheses. First, the age at which OA first becomes clinically symptomatic may reflect either the duration of exposure to specific risks, or different "latencies" between occupational groups. Second, occupations not previously described at risk of OA, such as housekeepers and truck drivers, indicates a need for refining our categories of risk. Finally, the disability and economic impact of $\mathrm{OA}$ due to occupation is much greater than anything described thus far. In the context where OA is potentially aetiologically linked to occupation in a sizeable segment of the population, our results contribute to the change of paradigm that OA can no longer be considered only a disease of ageing. OA and occupational history must be included into current and future longitudinal population studies of ageing in order to clarify the aetiological relation and propose preventive measures in specific occupations.

\section{ACKNOWLEDGEMENTS}

This study was made possible in part by the contribution of the Expanscience Laboratories, Courbevoie, France. The authors wish to thank M Jean-François Chastang and Ms Michèle Piccioti from INSERM unit 88, St-Maurice, France, for their assistance in coding and computing.

\section{Authors' affiliations}

M Rossignol, Department of Epidemiology, Biostatistics and Occupational Health, McGill University and Montreal Department of Public Health, Montreal, Canada

A Leclerc, INSERM, Unit 88, St-Maurice, France

F A Allaert, Cenbiothech, Dijon, France

S Rozenberg, B Fautrel, Rheumatology, Pitie-Salpetriere Hospital, Paris, France

J-P Valat, Faculty of Medicine, Tours University, France

B Avouac, Rheumatology, Henri Mondor Hospital, Créteil, France

P Hilliquin, Gilles de Corbeil Hospital, Corbeil, France

P Coste, Expanscience Laboratories, Courbevoie, France

B Savarieau, Nukleus Agency, Paris, France

\section{REFERENCES}

1 Lievense A, Bierma-Zeinstra S, Verhagen A, et al. Influence of work on the development of osteoarthritis of the hip: a systematic review. J Rheumatol 2001;28:2520-8.

2 Cooper C, McAlindon T, Coggon D, et al. Occupational activity and osteoarthritis of the knee. Ann Rheum Dis 1994;53:90-3.

3 Croft P, Cooper C, Wickham C, et al. Defining osteoarthritis of the hip for epidemiologic studies. Am J Epidemiol 1990;132:514-22.

4 Sandmark H, Hogstedt C, Vingard E. Primary osteoarthrosis of the knee in men and women as a result of lifelong physical load from work. Scand J Work Environ Health 2000;26:20-5.

5 Anderson JJ, Felson DT. Factors associated with osteoarthritis of the knee in the first national health and nutrition examination survey (Hanes I). Am J Epidemiol 1988;128:179-89.

6 Felson DT, Hannan MT, Naimark A, et al. Occupational physical demands, knee bending, and knee osteoarthritis: results from the Framingham study. J Rheumatol 1991;18:1587-92.

7 Holte HH, Tambs K, Bjerkedal T. Manual work as predictor for disability pensioning with osteoarthritis among the employed in Norway 1971-1990. Int J Epidemiol 2000;29:487-94.

8 Vingard E, Alfredsson L, Goldie I, et al. Occupation and osteoarthrosis of the hip and knee: a register-based cohort study. Int J Epidemiol 1991;20:1025-31.

9 Fautrel B, Hilliquin P, Allaert FA, et al. Prescription habits for osteoarthritis: results of a nation-wide pharmacoepidemiological survey of 10,000 patients. American College of Rheumatology, 64th annual meeting, November 2001.

10 INSEE. Social classification of occupations [in French]. Paris: INSEE, 1983; (in French).

11 Hebert F, Duguay P, Massicotte P, et al. Revised occupational categories for use in descriptive studies. Montreal, Quebec: Quebec Research Institute in Occupational Health and Safety, 1995 (in French).

12 Mormiche P. National survey on health impairment and disability. Courrier des statistiques, INSEE 1998;87:7-18 (in French).

13 Bernard PM, Lapointe C. Statistical measures in epidemiology. Québec: Presses de l'Université du Québec, 1987:287-8 (in French).

14 Cooper C, Campbell L, Byng P, et al. Occupational activity and the risk of hip osteoarthritis. Ann Rheum Dis 1996;55:680-2.

15 Thelin A, Jansson B, Jacobsson B, et al. Coxarthrosis and farm work: a casereferent study. Am J Ind Med 1997;32:497-501.

16 Lindberg H, Montgomery F. Heavy labor and the occurrence of gonarthrosis. Clin Orthop Rel Res 1987;214:235-6.

17 Manninen P, Heliovaara M, Riihimaki $\mathrm{H}$, et al. Physical workload and the risk of severe knee osteoarthritis. Scand J Work Environ Health 2002;28:25-32.

18 Lane NE. Physical activity at leisure and risk of osteoarthritis. Ann Rheum Dis 1996;55:682-4.

19 Lau EC, Cooper C, Lam D, et al. Factors associated with osteoarthritis of the hip and knee in Hong Kong Chinese: obesity, joint injury, and occupational activities. Am J Epidemiol 2000;152:855-62.

20 Vingard E. Osteoarthrosis of the knee and physical load from occupation. Ann Rheum Dis 1996;55:677-9. 